\title{
Auto-Imunidade ANCA (Anticorpo Anti-Citoplasma de Neutrófilos) Positiva Induzida por Propiltiouracil: Relato de Caso e Revisão da Literatura
}

\section{apresentação de caso}

\author{
NÁdila Cecyn Pietszkowski \\ Gisah amaral de Carvalho \\ HEVELYN NOEMBERG DE SOUZA \\ CLÁUDIO ROGÉRIO WERKA JR. \\ LuÍS AUGUSTO BORAZO \\ HANS GRAF \\ MaURicio de Carvalho
}

Serviço de Endocrinologia e Metabologia da Universidade Federal do Paraná - SEMPR, Curitiba, PR.

\begin{abstract}
RESUMO
A terapêutica com drogas antitireoidianas pode ser acompanhada de efeitos colaterais. Propiltiouracil (PTU) pode induzir vasculites anticorpo anti-citoplasma de neutrófilos (ANCA) positivas, na maioria das vezes relacionadas ao subtipo mieloperoxidase (ANCA-MPO). O nosso objetivo é relatar o caso de uma paciente com doença de Graves que desenvolveu auto-imunidade induzida por PTU, com manifestações cutâneas, pulmonares e renais, associadas à positividade do ANCA. O exame anátomo-patológico pulmonar revelou hemorragia difusa e a biópsia renal demonstrou glomeruloesclerose segmentar e focal. Foi tratada com pulsoterapia com corticóides e ciclofosfamida, com boa evolução clínica. Este caso enfatiza a necessidade de detecção e tratamento precoce deste efeito adverso relativamente raro do PTU. (Arq Bras Endocrinol Metab 2007;51/1:136-141)
\end{abstract}

Descritores: Vasculite; Propiltiouracil; ANCA

\section{ABSTRACT}

Antineutrophil Cytoplasmic Antibody (Anca)-Associated Autoimmune Disease Induced by Propylthiouracil.

Antithyroid drugs sometimes cause severe complications. Propylthiouracil (PTU) can be associated to ANCA positive vasculitis, most often related to myeloperoxidase subtype (ANCA-MPO). Our objective is to describe a female patient with Graves' disease, who developed PTU inducedautoimmune disease, with cutaneous, pulmonary, and renal lesions, associated with ANCA. Histopathological examination revealed diffuse pulmonary hemorrhage, and focal segmental glomerulosclerosis at the kidney biopsy. She was treated with systemic corticosteroid therapy and cyclophosphamide, with clinical improvement. This case highlights the need for greater awareness of this relatively rare adverse effect of propylthiouracil. (Arq Bras Endocrinol Metab 2007;51/1:136-141)

Keywords: Vasculitis; Propylthiouracil; ANCA
Recebido em 12/04/06 Aceito em 23/06/06
A TERAPIA COM DROGAS antitireoidianas (DAT), como propiltiouracil - (PTU) e metimazol (MTM), é comumente usada na Doença de Graves. Pode ser acompanhada de vários efeitos colaterais, tais como elevação de enzimas hepáticas, leucopenia, rash cutâneo e artralgias. Vasculites são consideradas efeitos colaterais raros (1).

As vasculites afetam vários órgãos e sistemas e são consideradas doenças sistêmicas. Podem ser primárias ou secundárias, sendo que as primeiras incluem as que envolvem grandes, médios ou pequenos vasos. $\mathrm{O}$ segundo grupo compreende aquelas relacionadas a doenças reumáticas ou auto-imunes, infecções, drogas, substâncias tóxicas e neoplasias. As drogas mais comumente associadas a vasculites são antibióticos, medicações anti- 
reumáticas não esteroidais, cloroquina, penicilamina, ouro, carbimazol, propiltiouracil, inibidores da enzima conversora da angiotensina e drogas citotóxicas (quimioterapia) (2-4).

Anticorpos anti-citoplasma de neutrófilos (ANCA) são importantes marcadores sorológicos para certas vasculites de pequenos vasos. Podem ser divididos em dois grupos, os anticorpos antimieloperoxidase (MPO), que produzem um padrão fluorescente perinuclear (p-ANCA), e os anticorpos anti-proteinase 3 (PR3), que produzem padrão citoplasmático à imunofluorescência. Anticorpos ANCA específicos para a proteinase 3 e mieloperoxidase estão associados com as vasculites necrosantes, especialmente com a Granulomatose de Wegener (GW), poliangeíte microscópica (PAM) e glomerulonefrite crescêntica idiopática (5).

Propiltiouracil pode induzir vasculites ANCA positivas, com a formação de auto-anticorpos policlonais, sendo a maioria relacionada com o ANCAMPO (ou ANCA-p), embora casos positivos para ANCA-PR3, elastase humana leucocitária e lactoferrina também possam ser observados. Habitualmente, com a retirada da medicação ocorre resolução dos sinais e sintomas e queda dos níveis de ANCA. Ocasionalmente, nos casos mais graves, há necessidade de administração de imunossupressores. Curiosamente, títulos altos ou ascendentes de ANCAMPO podem ser observados na fase de remissão, independentemente de recorrência clínica. Deve-se ressaltar ainda que a presença do ANCA, associada ou não à vasculite, pode ocorrer anos após o tratamento com o PTU. Outra questão controversa é a possibilidade do hipertireoidismo per se induzir a formação do ANCA $(3,6-9)$.

\section{RELATO DO CASO}

Paciente feminina de 43 anos, branca, com diagnóstico de Doença de Graves em tratamento com propiltiouracil (200 mg por dia) há dois anos, sem outras comorbidades, referiu aparecimento de máculas arroxeadas em membros inferiores há 4 meses, associadas a edema leve local, com duração de três dias e remissão espontânea posterior. Dois meses após houve aparecimento de pápulas avermelhadas e edema em membros inferiores, além de astenia e insônia. Nesta ocasião, a paciente procurou atendimento médico e realizou os exames demonstrados na tabela 1 . Foi proposto o diagnóstico de vasculite induzida pelo uso do PTU e a medicação foi suspensa. A cintilografia cervical anterior revelou glândula tireóide aumentada de tamanho, morfologia preservada, distribuição do radioiodo difusamente heterogênea e nível de captação em 24 horas de 54,2\%. A paciente foi submetida a dose terapêutica 131 iodo, com $25 \mathrm{mCi}$. Vinte e dois dias após a realização do iodo radioativo a paciente foi internada por dispnéia de moderada intensidade, iniciada há um dia, acompanhada de dor torácica ventilatório-dependente, sem tosse, febre ou lesões de pele associadas. Estava em uso de beta-bloqueador e anticoncepcional oral. Encontrava-se normotensa, com taquicardia e taquipnéia leves, mucosas hipocoradas, tireóide discretamente aumentada e sem nodulações, ausculta cardíaca normal, diminuição do murmúrio vesicular à direita com estertores crepitantes em terços médio e basal bilateralmente, além de edema de membros inferiores. Realizou raio-X de tórax, que demonstrou infiltrado pulmonar intersticial bilateral difuso (figura 1). Os principais exames laboratoriais da admissão estão resumidos na tabela 2 .

Tabela 1. Exames laboratoriais durante o início das manifestações cutâneas induzidas pelo PTU.

\begin{tabular}{lcc}
\hline TESTE & RESULTADO & VALOR DE REFERÊNCIA \\
Volume globular & $41,6 \%$ & $35-45 \%$ \\
Hemoglobina & $14,0 \mathrm{~g} / \mathrm{dl}$ & $12,0-15,5 \mathrm{~g} / \mathrm{dl}$ \\
VCM & $80,8 \mathrm{fl}$ & $80-100 \mathrm{fl}$ \\
VHS & $128 \mathrm{~mm} \mathrm{em} 1 \mathrm{hora}$ & $1-20 \mathrm{~mm} / \mathrm{hora}$ \\
Proteína C reativa & $26 \mathrm{mg} / \mathrm{dl}$ & $1,9-2,5 \mathrm{mg} / \mathrm{dl}$ \\
Creatinina & $0,87 \mathrm{mg} / \mathrm{dl}$ & $0,6-1,2 \mathrm{mg} / \mathrm{dl}$ \\
& traços de proteína & Negativo até + \\
Parcial de urina & 42.000 hemáceas $/ \mathrm{ml}$ & Até 6.000 hemáceas $/ \mathrm{ml}$ \\
& 5.000 leucócitos $/ \mathrm{ml}$ & Até 12.000 leucócitos $/ \mathrm{ml}$ \\
Crioglobulina & Ausência de cilindros & Ausência de cilindros \\
C-ANCA & negativa & Negativa \\
P-ANCA & negativo & Negativo \\
\hline
\end{tabular}


Pietszkowski et al.

A tomografia de tórax mostrou opacidades com padrão de vidro fosco centrais nos pulmões e sinais de hipertensão pulmonar, compatíveis com vasculite ou hemorragia pulmonar, com padrão de dano alveolar difuso (figura 2). O lavado broncoalveolar revelou sangue vivo na luz brônquica, 200 leucócitos, $19 \%$ de neutrófilos, $21 \%$ de linfócitos, $13 \%$ de macrófagos e macrófagos com hemossiderina em $47 \%$ das células desta linhagem. As culturas foram negativas. A biópsia, através da fibrobroncoscopia, demonstrou hemorragia antiga (hemossiderina) em luz de alvéolos e parede alveolar, com escassos vasos, a maioria deles apresentando rompimento de membrana basal. Endoscopia digestiva alta revelou lesão polipóide do cárdia, com exame anátomopatológico compatível com pólipo gástrico hiperplásico. A espirometria foi normal e os volumes pulmonares apresentaram discreta redução do volume de reserva expiratório e da capacidade residual funcional, além de estudo difusional no limite inferior da normalidade. O ecocardiograma demonstrou ventrículo esquerdo pouco hipertrofiado, com dimensão interna e função sistólica normais. Realizou biópsia renal, que revelou quadro histopatológico sugestivo de glomeruloesclerose segmentar e focal.

A paciente foi submetida a transfusão de concentrado de hemácias, pulsoterapia com metilprednisolona (500 $\mathrm{mg}$ IV ao dia por três dias) e ciclofosfamida $850 \mathrm{mg}$ IV, com boa resposta. Após a alta hospitalar, foi tratada com prednisona em doses progressivamente menores e com pulsos mensais (três pulsos) de ciclofosfamida, com melhora clínica e radiológica pulmonar. Dois meses após o iodo radioativo, desenvolveu hipotireoidismo e foi iniciada terapêutica com levotiroxina.

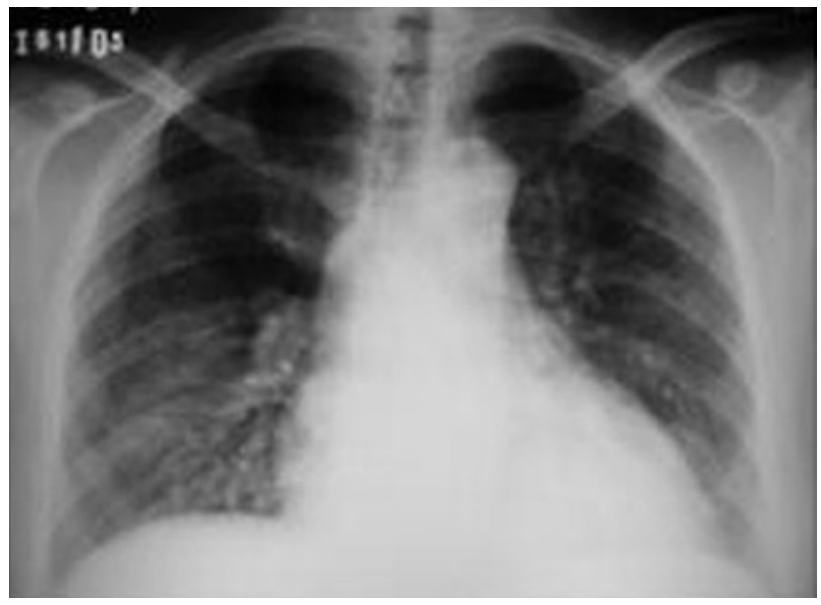

Figura 1. Raio-X de tórax com infiltrado intersticial difuso, sinal de vasculite pulmonar.

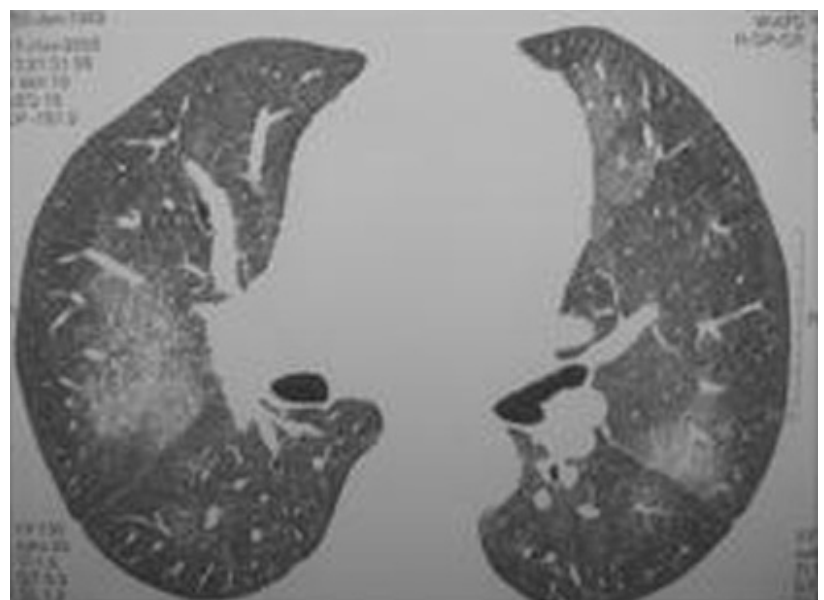

Figura 2. Tomografia de tórax com opacidades em padrão de vidro fosco centrais, padrão de dano alveolar difuso.

Tabela 2. Exames laboratoriais durante a admissão com quadro de vasculite renal e pulmonar por PTU.

\begin{tabular}{lcc}
\hline EXAME & RESULTADO & VALOR DE REFERÊNCIA \\
Volume globular & $22 \%$ & $35-45 \%$ \\
Hemoglobina & $6,6 \mathrm{~g} / \mathrm{dl}$ & $12,0-15,5 \mathrm{~g} / \mathrm{dl}$ \\
VCM & $66 \mathrm{fl}$ & $80-100 \mathrm{fl}$ \\
Creatinina & $1,2 \mathrm{mg} / \mathrm{dl}$ & $0,6-1,2 \mathrm{mg} / \mathrm{dl}$ \\
& Traços de proteína & Negativo até + \\
Parcial de urina & 90.000 hemáceas $/ \mathrm{ml}$ & Até 6.000 hemáceas $/ \mathrm{ml}$ \\
& 15.000 leucócitos $/ \mathrm{ml}$ & Até 12.000 leucócitos $/ \mathrm{ml}$ \\
Urocultura & Ausência de cilindros & Ausência de cilindros \\
Proteinúria de 24 horas & Negativa & Negativa \\
TSH & $220 \mathrm{mg}$ & Até $100 \mathrm{mg}$ \\
T4 livre & $0,079 \mathrm{mUl} / \mathrm{ml}$ & $0,4-4 \mathrm{mUl} / \mathrm{ml}$ \\
T3 & $2,63 \mathrm{ng} / \mathrm{ml}$ & $0,7-1,8 \mathrm{ng} / \mathrm{ml}$ \\
\hline
\end{tabular}




\section{DIscussão}

O primeiro caso de vasculite ANCA-positiva induzida por PTU (VPTU) foi descrito em 1993. Após o relato inicial, foram descritas várias manifestações clínicas associadas, como por exemplo perda neurossensorial auditiva (10), vasculite de sistema nervoso central (5), manifestações pulmonares (desde mínimo envolvimento nasal até hemorragia alveolar difusa, pneumonia intersticial e capilarite pulmonar) (11-16), esclerite (11), lesões cutâneas (incluindo dermatose neutrofilica e pioderma gangrenoso) (11,17-19), glomerulonefrite rapidamente progressiva $(20,21)$, nefropatia por $\operatorname{IgA}$ (22), síndrome lupus-like (23), policondrite (17), entre outras. Proteinúria e/ou hematúria ocorre em $67 \%$ dos casos, artralgias em $48 \%$, febre em $37 \%$, alterações de pele em 30\% e sintomas pulmonares em 26\% (5).

Relatamos um caso de auto-imunidade induzida por PTU, com manifestações cutâneas, hemorragia pulmonar com dano alveolar difuso e glomerulonefrite. Houve necessidade de tratamento imunossupressor com corticoesteróide e ciclofosfamida, até a melhora clínica, o que demonstra categoricamente o potencial do PTU em causar vasculites graves.

As vasculites sistêmicas induzidas por drogas (VSID) são raras e a sua incidência anual é de aproximadamente 9,5 por milhão (Alemanha). O curso clínico e sorológico das VSID e das vasculites idiopáticas é bastante similar, porém as primeiras ocorrem em pacientes mais jovens, têm evolução mais branda, com menos recidivas e freqüentemente não necessitam terapia com drogas citotóxicas (6,7). As VSID apresentam mais freqüentemente manifestações cutâneas, enquanto as vasculites idiopáticas têm uma maior prevalência de lesão renal. Porém, é difícil a distinção anátomo-patológica entre as duas, pois ambas apresentam leucocitoclasia e necrose fibrinóide dos vasos sangüíneos $(6,7)$.

A patogênese das vasculites sistêmicas não é bem compreendida. Entretanto, tem sido demonstrado que os neutrófilos ANCA-ativados contribuem para o dano proteolítico e oxidativo dos vasos sangüíneos, através da ativação de células in vitro como monócitos e células endoteliais, indução de autoimunidade ou alteração da configuração da MPO $(3,5,6,11)$. Ainda em relação à patogênese, sabe-se que elevações dos títulos de ANCA se correlacionam com o risco de surtos de doença futuros, porém sem prever o momento em que isso irá ocorrer (4). O ANCA-PR3 apresenta alta especificidade (99\%) para a Granulomatose de Wegener, enquanto o ANCAMPO perinuclear é um bom marcador sorológico para a poliangeíte microscópica. Pode ser encontrado também em pacientes com lupus eritematoso sistêmico, artrite reumatóide e VSID.

A distribuição das subclasses de IgG e sua avidez são diferentes entre pacientes com vasculites primárias e induzidas por PTU. Neste grupo, reconhece-se um conjunto mais restrito de epítopos, sugerindo que o mecanismo de produção do ANCA é diferente nestas duas situações, o que poderia justificar as diferenças clínicas existentes entre elas $(7,24)$. A prevalência do ANCA em pacientes tratados com drogas antitireoidianas varia de 4 a $46 \%$. Somente um quinto dos pacientes ANCA-positivos induzidos por PTU apresentam manifestação clínica de vasculite, ou seja, a presença do ANCA isoladamente não é suficiente para a indução de vasculite $(3,25)$. Especula-se que possam existir fatores séricos influenciando na atividade da doença, como por exemplo positividade para anticorpo anti-células endoteliais ou ainda diferenças nas características do ANCA (subclasses de IgG e avidez) $(3,26)$.

A média de idade destes pacientes é de 44 anos, com $74 \%$ de acometimento feminino, o que reflete a preponderância de tireoidopatias nas mulheres (11). Disfunção renal e artralgias são as manifestações mais comuns, e o padrão específico do ANCA é o perinuclear ou MPO em cerca de $94 \%$ dos casos. O PTU é o responsável por cerca de $93 \%$ das vasculites induzidas por tionamidas. Relatos da literatura mostram que há melhora clínica em 85 a 93\% dos pacientes com VSID por PTU após a suspensão da medicação, e que a duração média do uso da droga antes da apresentação clínica é de 35 meses, enquanto apenas 33\% receberam a droga por menos de 18 meses. Desta forma, o uso prolongado das tionamidas aumenta o risco deste grave efeito colateral. Deve-se notar que a remissão clínica pode preceder a negativação do $\operatorname{ANCA}(5,6,27)$.

O tratamento apropriado da VPTU depende da severidade da doença. O primeiro passo, obviamente, consiste na retirada da droga, geralmente resultando na melhora da fadiga, febre, mialgias e alterações cutâneas. As manifestações renais graves, rapidamente progressivas ou com biópsia que revele glomerulonefrite com crescentes necessitam de corticóide e/ou ciclofosfamida, ou ainda plasmaferese. $\mathrm{Na}$ maioria dos casos, a função renal melhora, porém o clearance de creatinina pode não retornar ao valor basal (11). Estas últimas medidas terapêuticas podem ser utilizadas também em lesões pulmonares severas e com risco de vida. Em geral, os títulos de ANCA correlacionam-se com a resposta ao tratamento e com a atividade da doença (28). 
$\mathrm{Na}$ vigência de tratamento prolongado com PTU, foram preconizadas dosagens periódicas do ANCA, visando influenciar nas decisões terapêuticas do hipertireoidismo. Entretanto, a positividade para o ANCA não prevê necessariamente o surgimento de sintomas e sinais de vasculite $(5)$.

A prevalência de ANCA-MPO nos usuários de drogas antitireoidianas varia de $25-60 \%$ nos pacientes tratados com PTU, e de $3,4 \%$ nos tratados com metimazol (29-31). Em uma análise, Sato e cols. demonstraram positividade para o ANCA-p em 6,7\% dos pacientes antes do tratamento, $64 \%$ nos tratados com PTU e em nenhum dos tratados com metimazol. O ANCA-p teve uma correlação significativa com o anticorpo antitireoglobulina e não houve correlação com o anticorpo anti-tireoperoxidase, sugerindo que a severidade da Doença de Graves pode ser um fator responsável para positividade do ANCA-p (1). A proporção de pacientes positivos para este anticorpo aumenta com a duração da terapia, porém não há correlação com idade ou sexo (29). Da mesma forma, não foi relatado aumento da prevalência do ANCA em pacientes com tireoidite de Hashimoto (30).

Considerando que a positividade ANCA-MPO é alta tanto antes como durante o tratamento com DAT, sobretudo com o PTU, e que uma pequena parcela dos pacientes evoluem para o quadro clínico de vasculite, sugere-se que a sua pesquisa deva ser realizada naqueles recebendo a medicação por mais que 18 meses. Igualmente, aqueles pacientes que desenvolvem sinais e sintomas suspeitos de vasculite devem realizar a dosagem e, conforme os títulos dos anticorpos, necessitam avaliação quanto à suspensão da medicação e encaminhamento para tratamento definitivo do hipertireoidismo $(12,15)$.

\section{CONCLUSÃO}

A presença do ANCA (e vasculite associada) não é incomum em pacientes tratados com PTU e existe maior probabilidade de auto-imunidade quanto maior for a duração do tratamento. Este risco deve ser levado em consideração no manejo de pacientes com hipertireoidismo. Lesões cutâneas, hematúria e/ou proteinúria, ou ainda queixas pulmonares demandam avaliação rigorosa, inclusive com suspensão do PTU. A retirada da droga é habitualmente suficiente para promover a remissão da vasculite. Entretanto, nos casos mais graves, terapêutica imunossupressora pode ser necessária.

\section{REFERÊNCIAS}

1. Sato $H$, Hattori $M$, Fujieda $M$, Sugihara $A$, Inomata $H$, Hoshi $M$, et al. High prevalence of antineutrophil cytoplasmic antibody positivity in childhood onset Graves' disease treated with propylthiouracil. J Clin Endocrinol Metab 2000;85:4270-3.

2. Gaburri PD, Chebli JMF, Attalla A, Pereira CMN, Bonfante HL, Martins-junior EV, et al. Colonic ulcers in propylthiouracil induced vasculitis with secondary antiphospholipid syndrome. Postgrad Med J 2005;81:338-40.

3. Slot M, Links TP, Stegeman CA, Tervaert JWC. Occurrence of antineutrophil cytoplasmic antibodies and associated vasculitis in patients with hyperthyroidism treated with antithyroid drugs: a long-term follow-up study. Arthritis Rheum 2005;53:108-13.

4. Choi HK, Merkel PA, Walker AM, Niles JL. Drug associated antineutrophil cytoplasmic antibody positive vasculitis: prevalence among patients with high titers of antimyeloperoxidase antibodies. Arthritis Rheum 2000;43:405-13.

5. Vanek C, Samuels MH. Central nervous system vasculitis caused by propylthiouracil therapy: a case report and literature review. Thyroid 2005; $15: 80-4$.

6. Bonaci-Nikolic B, Nikolic MM, Andrejevic S, Zoric S, Bikilica M. Antineutrophil cytoplasmic antibody (ANCA)-associated autoimmune diseases induced by antithyroid drugs: comparison with idiopathic ANCA vasculitides. Arthritis Res Ther 2005;7:1072-81.

7. Gao Y, Ye H, Yu F, Guo X-H, Zhao M-H. Anti-myeloperoxidase IgG subclass distribution and avidity in sera from patients with propylthiouracil-induced antineutrophil cytoplasmic antibodies vasculitis. Clin Immunology 2005;117:87-93.

8. Guma M, Salina S, Reverter JL, Roca J, Valls-Roc M, Juan M, et al. Frequency of antineutrophil cytoplasmic antibody in Graves' disease patients treated with methimazole. J Clin Endocrinol 2003;88:3141-6.

9. Morita S, Ueda Y, Eguchi K. Anti-thyroid drug induced ANCA associated vasculitis: a case report and review of the literature. Endocr J 2000;47:467-70.

10. Thamprajamchit S, Jariengprasert C, Rajatanavin R. Propylthiouracil-induced sensorineural hearing loss associated with antineutrophil cytoplasmic antibodies. Endocr Pract 2004;10:432-7.

11. Gunton JE, Stiel J, Caterson RJ, McElduff A. Anti-thyroid drugs and antineutrophil cytoplasmic antibody positive vasculitis. A case report and review of the literature. J Clin Endocrinol Metab 1999;84:13-6.

12. Dhillon SS, Singh D, Doe N, Oadri AM, Ricciardi S, Schwarz MI. Diffuse alveolar hemorrhage and pulmonary capillaritis due to propylthiouracil. Chest 1999;116:1485-8.

13. Tsai MH, Chang YL, Wu VC, Chang CC, Huang TS. Methimazole induced pulmonary hemorrhage associated with antimyeloperoxidase antineutrophil cytoplasmic autoantibody: a case report. J Formos Med Assoc 2001;100:772-5.

14. Yamauchi K, Sata M, Machiya J, Osaka D, Wada T, Abe S, et al. Antineutrophil cytoplasmic autoantibody positive alveolar hemorrhage during propylthiouracil therapy for hyperthyroidism. Respirology 2003;8:532-5.

15. Ohwada R, Kato K, Ohmori K, Isosaki O, Hotta M, Ono M, et al. A man with interstitial pneumonia due to propylthiouracil. Inter Med 2003;42:1026-30.

16. Nakamoro $Y$, Tominaga $T$, Inoue $Y$, Shinohara K. Propylthiouracil induced associated with antineutrophil antibody against myeloperoxidase. Inter Med 2003;42:463-4.

17. Vazel-Boulenger A, Kupfer-Bessaguet I, Gouedard C, Leberre R, Leroy JP, Sonnet E, et al. Neutrophilic dermatosis associated with propylthiouracil-induced p-ANCA. Ann Dermatol Venereolol 2005; 132:27-31.

18. Jacobs EM, Hartkemp A, Kaasjager HA. PTU associated cutaneus vasculitis with ANCA anti-MPO and anti PR3 antibodies. Neth J Med 2003;61:296-9.

19. Hong SB, Lee MH. A case of propylthiouracil induced pyoderma gangrenosum associated with antineutrophil cytoplasmic autoantibody. Dermatology 2004;208:339-41. 
20. Kudoh Y, Kuroda S, Shimamoto K, limura O. Propylthiouracil induced rapidly progressive glomerulonephritis associated with antineutrophil cytoplasmic antibodies. Clin Nephrol 1997;48:41-3.

21. Kitara T, Hiromura K, Maezawa A, Ono K, Narabara N, Yano S, et al. Case of propylthiouracil induced vasculitis associated with antineutrophil cytoplasmic antibodies; review of literature. Clin Neprhol 1997;47:336-40.

22. Winters MJ, Hurley RM, Lirenman DS. ANCA positive glomerulonephritis and $\lg A$ nephropathy in a patient on propylthiouracil. Pediatr Nephrol 2002;17:257-60.

23. Yamada A, Sato K, Tochimoto A, Takagi S, Hizuka N, Takano K. Propylthiouracil induced lupus-like syndrome developing in a Graves patient with a sibling with systemic lupus erytematosus. Intern Med 2002;41:1204-8.

24. Ye H, Guo X-H, Zhao M-H, Gao Y, Zhang Y, Gao Y. Epitope mapping of myeloperoxidades antibodies in propylthiouracilinduced vasculitis and microscopic polyangiitis. Zhonghua Nei Ke ZA ZHI 2004;43:915-9.

25. Noh JY, Asari T, Hamada N, Ishikawa N, Abes H, Ito K. Frequency of appearance of myeloperoxidades-antineutrophil cytoplasmic antibodies (MPO-ANCA) in Graves's disease patients treated with propylthiouracil and the relationship between MPO-ANCA and clinical manifestations. Clin Endocrinol 2001;54:651-4.

26. Yu F, Zhao Mh, Zhang YK, Zhang Y, Wang HY. Anti-endothelial cell antibodies with propylthiouracil-induced ANCA positive vasculitis are associated with disease activity. Clin Exp Immunol 2005;139:569-74.

27. Gunton JE, Clifton-Bligh P, Wilmshurst E, McEldulff A. Prevalence of antineutrophil cytoplasmic antibody in patients receiving antithyroid medication. Eur J Endocrinol 2000;142:587-90.
28. Fujieda M, Hatori M, Kurayama H. Clinical features and outcomes with antineutrophil cytoplasmic auto antibody positive glomerulonephritis with on propylthiouracil treatment. J Am Soc Nephrol 2002;13:437-45.

29. Sera N, Ashizawa K, Ando T, Abe Y, Ide A, Usa T, et al. Treatment with propylthiouracil is associated with appearance of antineutrophil cytoplasmic antibodies in some patients with Graves disease. Thyroid 2000;10:595-9.

30. Harper L, Chin L, Daykin J, Allahabadia A, Heward J, Gough C, et al. Propylthiouracil and carbimazole associated antineutrophil cytoplasmic antibodies in Patients with Graves's disease. Clin Endocrinol 2004;60:671-5.

31. Wada N, Mukai M, Kohno M, Notoya A, Ito T, Yoshioka N. Prevalence of serum anti-myeloperoxidades antineutrophil cytoplasmic antibodies in patients with Graves's disease treated with propylthiouracil and thiamazole. Endocr J 2002;49:329-34.

Endereço para correspondência:

Gisah Amaral de Carvalho

Serviço de Endocrinologia e Metabologia

Av. Agostinho Leão Junior 285

80030-110 Curitiba, PR.

Fax: (41) 3360-7876

E-mail: carvalho@mais.sul.com.br 